\title{
Developing Leader Behaviours among the Students of an Educational Leadership Programme
}

\author{
Martin Thomas * $\quad$ Margaret Madden ${ }^{\dagger}$
}

\begin{abstract}
Educationists have been showing considerable interest in knowing factors affecting leader effectiveness. In the midst of ineffective educational leadership and educational leadership development programmes, leader behaviours are considered one of the important predictors of leadership effectiveness and thus to be developed in educational programmes. This One-Group Pretest-Posttest Experimental Research explored the extent to which the participation in a course unit of the Educational Leadership Programme, offered by the Centre of Educational Leadership Development (CELD), Karachi, Pakistan, developed the required leader behaviours among the postgraduate level students. Fleishman's Leadership Opinion Questionnaire (Pierce $\mathcal{E}$ Newstrom, 2005a) was used for the pretest and the posttest. Participants of the research were eighty four (84) Postgraduate Certificate in Educational Leadership or Master of Educational Leadership students, who studied the Perspectives of Leadership unit. It was expected that this unit would not only assist students to build the strong knowledge base and acquire certain leadership skills, but also develop high level of appropriate behaviours which would prepare them to cope with the scope of the challenges which face them as well as create or maintain a positive, thriving organisational climate in their schools. Contrary to expected outcomes, the research revealed that the unit participants exhibited significant but relatively moderate orientation towards the expected leader behaviours. The research has challenged the legitimacy of the approaches used to teach the course and recommended a thorough study of the factors that contribute to the development of leader behaviours among leadership students.
\end{abstract}

Keywords: Leader behaviours, initiating structure, consideration behaviour, leadership skills, organizational climate.

\section{Introduction}

School principals are considered leaders of human resource development as they assist, lead and motivate the school staff (Hashmi, 2015). Thus factors influencing leader effectiveness have increasingly become an area of considerable interest amongst educationists who concede that possessing simple knowledge about the role, function and skills of leadership does not necessarily produce good educational leaders (Robert, 2012). Where a study by Guo, Dai, and Yang (2016) found insignificant relationship between task-behaviour, relationship behaviour and job performance, outcomes of other research studies such as Judge and Piccolo and Judge, Piccolo and Ilies, indicated that leader behaviours are fundamental predictors of effective leadership (Derue, Nahrgang, Wellman,

\footnotetext{
*Iqra University, Karachi, Pakistan. E-mail: martin.thomas@iuk.edu.pk

${ }^{\dagger}$ Iqra University, Karachi, Pakistan.
} 
\& Humphrey, 2011) as employees' attitudes, behaviours, emotions, morale and perception are influenced by the way they observe their leaders behave (Momeni, as cited in (Holloway, 2012)). The work of Derue et al. (2011) indicates that leader behaviours speak a more definitive language of effectiveness than do leader traits. Consequently behaviours either channel the creation and maintenance of a positive, thriving organizational climate or they fail to do so and produce negative effects (Holloway, 2012). The behavioural work ethic of leaders, exhibited in their confidence, high energy, personal conviction, positive use of power and assertiveness, builds the self-belief and confidence of those they lead (Tabbodi \& Prahallada, 2009) and acts as an extrinsic motivator that breeds extra effort amongst employees (Webb, 2007) and satisfaction with their supervisors (Robert, 2012).

Educational leadership programmes are known to have considerable effect on educational leaders' behaviour development and consequently school improvement. A range of proponents of educational leadership programmes, however, prefer self-initiated participation of individuals in leadership programmes over imposed mandatory participation (Schleicher, 2012) as the former can infuse more motivation among the programme participants than the latter one. Educational programmes remain ineffective if they do not meet the needs of the participants of the programmes. For example, (Loew \& Wentworth, 2013) found that leadership concerns appeared to be a great factor that impacted hiring, retention and performance of the workforce. Loe and Wentworth further indented that almost 75 percent of the organizations participated in a survey rated their leadership programmes ineffective. This One-Group Pretest-Posttest Experimental Research explored the extent to which self-initiated participation of students in a course unit of the Educational Leadership Programme offered by the Centre of Educational Leadership Development (CELD), Karachi, Pakistan (pseudonym), developed the knowledge and practice of required leader behaviours among students undertaking the Postgraduate Certificate in Educational Leadership or Masters in Educational Leadership courses.

\section{Review of Related Literature}

\section{Leader Behaviours}

Researchers have identified various leader behaviours including authoritarian, democratic and laissez-faire as described in the Iowa studies; initiating structure and consideration in the Ohio State studies; along with the Michigan studies' recognition of productioncentred and employees-centred (Lunenburg \& Ornstein, 2012). Such behaviour patterns help form the identity of a leader in action as well as dictate the relational interplay between leaders and followers and the functioning of the organization in which they are engaged. Blake and Mouton extended the initiating structure and consideration dimensions of the Ohio State studies and developed a Leadership Grid as a simple tool to help leaders assess their manner of working with those for whom they hold management responsibilities. The five leadership behaviours or styles identified by Blake and Mouton included: (1) The impoverished leader who has low concerns for both production and people; (2) The authority compliance leader who shows high concern for production and 
low concern for people; (3) The country-club leader who exhibits a high concern for people and low concerns for production; (4) The middle-of-the-road leader who demonstrates blended and medium concerns for both production and people; and (5) The team leader who expresses high concerns for both production and people (Lunenburg \& Ornstein, 2012; Lussier \& Achua, 2007). An investigation of these styles of leadership was a component of both the knowledge content of the unit of study and the research data gathering design.

Fielder's theoretical position presents an illustration of the reciprocal link between a leader's consistent system of interaction and the group with whom he/she works as a determinant of the favourableness of the work environment. The use of Fielder's least preferred co-worker (LPC) scale assists in determining the orientation of a leader's preferred behaviour towards either achieving quality interpersonal relationships or successful task performance. House, also a contingency theorist, advocates servant leadership and his path-goal model demonstrates a leader's behaviour as not power driven but as facilitating, enabling employees to reach their and the organisation's goals. House terms effective leader behaviours as: (1) directive leadership which informs co-workers what is expected of them; (2) supportive leadership encourages the creation of a friendly and approachable environment where leaders are concerned with the needs and well-being of co-workers; (3) participated leadership ensures that co-workers are consulted and their ideas are incorporated into decision making; and (4) achievement-oriented leadership sets targets for co-workers and shows confidence in their abilities to achieve them. Tannenbaum and Schmidt conceived a leadership behaviour continuum representing the degree of leader authority used ranging from the boss-centred to the subordinates-centred or autocratic to laissez-faire leadership behaviour. They depicted five typical leadership styles identifiable along the continuum, namely: telling, in which the leader identifies a problem and suggests a solution; selling, in which the leader persuades the group to accepts solutions; testing, where the leader identifies a problem, proposes a tentative solution and asks for the reactions of those who will implement it; consulting, means the leader presents the problem and asks the subordinates to identify a number of solutions and then selects the most appropriate one; and joining, where the leader becomes one of the members of the group to make decisions (Lunenburg \& Ornstein, 2012; Lussier \& Achua, 2007). In deciphering some of leader behaviours that encourage co-workers' satisfaction and commitment, Folkman's research presented effective leaders as those whose way of acting inspire and motivate others; strive for a pre-determined result; communicate a strategic perspective; work in collaboration; walk the talk; trust the co-workers' abilities to perform the tasks; develop and support others; and build relationship and courage among the employees and between the employees and the leader (Folkman, 2010).

The theoretical insights and measurement scales of the characteristics of leader behaviour indicate that they can be categorised in two main groups, namely, initiating structure behaviour and consideration behaviour, both of which bring employee satisfaction (Robert, 2012; Hamid, Ab Rahman, \& Nor, 2012). Fleishman et al. (as cited in Burke et al. (2006)), in support of the dichotomy of leadership behaviours, identified 65 different leader behaviours which can be categorized in two main groups. These comprise leadership behaviours which deal with task accomplishment or the task-focused category 
and those which facilitate team interaction and/or development which form the personfocused category. Task-oriented behaviour is similar to initiating structure (Robert, 2012; Hamid et al., 2012) and the person-focused behaviour reflects consideration behaviour (Robert, 2012; Hamid et al., 2012).

\section{Development of Leader Behaviours}

A constructive organizational climate is positively correlated with workers' motivation and their efficacy (Webb, 2007; Tabbodi \& Prahallada, 2009; Robert, 2012) and leader behaviours (Holloway, 2012), Enhancing workers' motivation and efficacy is contingent on the match between leader's behaviour and co-workers needs. Moorthy (2014) noted that a significant percentage of workforces in the current scenarios of the workplaces is a youngest cohort, who were born after 1980, and are known as the millennials or Generation Y. They demand more perks, faster promotion and greater work-life benefits than other generations. This implies that educational leaders need to develop a leader behaviour which is more flexible and motivating. Petrie (2014), on the other hand, differentiated between horizontal and vertical development and argued that horizontal leadership development demands focusing on developing technical skills, abilities and behaviours whereas vertical development requires developing critical and analytical thinking skills among the leaders so that they can understand the world around them. The inference for leadership programmes, therefore, is that they must overtly emphasize the development of both initiating-structure behaviour that encourages leaders to acquire technical skills of managing organizational activities and consideration behaviour that allows leaders to critically examine needs of both the organization and co-workers and motivate coworkers to channelize their skills, abilities and behaviours towards the development of the organization.

For the development of leader behaviours among the potential and practicing educators in Pakistan, three courses were introduced by CELD under its Educational Leadership Programme umbrella and offered in a mixed mode fashion. These courses include the Master of Educational Leadership, the Postgraduate Certificate in Educational Leadership and the Graduate Certificate in Educational Leadership. The leadership courses aimed to provide candidates with values, attitudes, knowledge and skills in educational leadership that could enable them to infuse their systems and organisations with a commitment to the highest ethical and moral standards and, at the same time, facilitate efficient and effective leadership and administrative practices.

The current One-Group Pretest-Posttest Experimental Research Design was conducted with those educational leadership participants who studied the unit entitled, Perspectives of Leadership (Fraenkel, Wallen, \& Hyun, 2012). The research aimed to find out the extent to which the learning gained through this particular unit of study with its philosophical and theoretical focus, was informative and practically effective in enabling its participants to develop both initiating-structures and consideration behaviours in their work settings. The Perspectives of Leadership was the first unit studied by the participants selected for the CELD Educational Programme's three (3) years pilot study. Insights gained from previous research studies (such as (Waqar \& Siddiqui, 2008)), anticipated that educational 
leadership students selected from the private sector schools across Pakistan would exhibit reasonably high levels of expected initiating-structure behaviour. These were anticipated as assigning different tasks to employees and guiding them to complete their tasks within the given time as well as consideration behaviour, such as, treat employees equally and involving them in decision making. The CELD Educational Programme had a crucial intent not only to develop leadership skills but also to inculcate moral and ethical leadership values in its participants along with the development of people-oriented, consideration or transformational leader behaviours (Khan, Ramzan, Ahmed, \& Nawaz, 2011).

\section{Conceptual Framework}

Pierce and Newstrom (2005b) cited Fleishman who offers a Leadership Opinion Questionnaire whose eight statements explore personal leadership orientation. Four of the eight statements focus on initiating-structure leader behaviour and four focus on consideration leader behaviour. Respondents are expected to indicate on a five point scale, the frequency of their engagement in the particular behaviour. To determine the effect of treatment in the current experimental research, the Leadership Opinion Questionnaire suggested by Fleishman was administered before and after the treatment.

The Perspectives of Leadership unit was offered in a mixed mode fashion where students attended two weeks' full time face-to-face sessions; followed by the first round of two and half months field work; a two days' check point after the first round of field work; second round of two and half months field work; and one day evaluation session at the completion of the unit. During the face-to-face sessions, the educational leadership students explored historical, organizational and evolving perspectives of educational leadership and critically examined theoretical underpinnings of these three perspectives. During the field work, these students applied various theories in their schools and reflected on the processes and outcomes of the application and later shared their learning from the field work during the check point and evaluation sessions. The educational leadership students participating in the unit were engaged either in leadership positions in different private schools of Pakistan or they were potential leaders, earmarked for a school or system leadership position. The pretest enabled the researchers to identify the students' frequency of engagement in initiating-structure behaviour or consideration behaviour while performing their leadership roles prior to participating in the unit of study or it identified their opinions about the engagement of leaders in these behaviours. The posttest determined the effect of the intervention, namely their workplace behaviours after completing the unit of study.

The following research question and hypotheses guided the analysis of data.

To what extent was the Perspectives of Leadership course unit of the CELD Educational Leadership Programme effective in developing initiating-structure and consideration behaviours to be demonstrated among its participants?

$$
\begin{aligned}
& H o_{1}=\mu_{1}-\mu_{2}=0 \\
& H o_{2}=\mu_{3}-\mu_{4}=0
\end{aligned}
$$




$$
\begin{aligned}
& H o_{3}=\mu_{1}=\mu_{2} \\
& H o_{4}=\mu_{3}=\mu_{4}
\end{aligned}
$$

Where, $\mu_{1}$ =population mean for average pretest (consideration), $\mu_{2}=$ population mean for posttest (consideration) and $\mu_{3}=$ population mean for pretest (nitiating structure) $\mu_{4}=$ population mean for posttest (nitiating structure).

Figure 1 illustrates the conceptual framework underpinning the study adapted from Fraenkel et al. (2012).

Figure 1

\begin{tabular}{|c|c|c|}
\hline $\begin{array}{l}\text { O } \\
\text { Pretest } \\
\text { Focus: Leader Behaviours } \\
\text { [Dependent Variables, DV) } \\
\text { - } \quad \text { Fleishman's Leadership } \\
\text { Opinion Questionnaire } \\
\text { (Fleishman, as cited in } \\
\text { Pierce, 2005) focused on } \\
\text { Initiating structure and } \\
\text { Consideration leader } \\
\text { behaviours (RQ) }\end{array}$ & $\begin{array}{l}\quad \mathrm{x} \\
\quad \text { Intervention } \\
\text { Focus: Development of the } \\
\text { required Leader Behaviours } \\
\text { [Independent Variable, IV] } \\
\text { - Teaching of Perspectives } \\
\text { of Leadership unit in a } \\
\text { mixed mode fashion }\end{array}$ & \begin{tabular}{l}
\multicolumn{1}{c}{ O } \\
Posttest \\
Focus: Leader Behaviours \\
[Dependent Variables, DV] \\
- $\quad$ Fleishman's Leadership \\
Opinion Questionnaire \\
(Fleishman, as cited in \\
Pierce, 2005) focused on \\
Initiating structure and \\
Consideration leader \\
behaviours (RQ)
\end{tabular} \\
\hline
\end{tabular}

Conceptual Framework

\section{Methodology}

\section{Research Design}

The current research was guided by the One-Group Pretest-Posttest Experimental design. A single group was measured before and after their exposure to a treatment or intervention, in this instance a unit of study in a piloted educational leadership course. When contrasted with the One-Shot Case Study Experimental design, in which a single group is exposed to a treatment and dependent variable is subsequently observed or measured to assess the effect of the intervention, the One-Group Pretest-Posttest design is considered of more value. The most obvious weakness of the former design is the absence of a researcher's control over the variables and he/she has no way of knowing whether or not the result obtained through observation is a direct outcome of the treatment. In the latter design, however, the researcher can establish with credibility the direct relationship between the change and the treatment (Fraenkel et al., 2012). 


\section{Instrument}

The Fleishman's Leadership Opinion Questionnaire (Fleishman, as cited in (Pierce \& Newstrom, 2005b)) was used for the pretest and posttest in the current research. The Fleishman's Leadership Opinion Questionnaire had two sets of statements. Statements 1 to 4 focused on consideration leader behaviour and the respondents indicated the frequency of their engagement in the behaviour by encircling the choices from 1 to 5 where 1 represented the highest frequency and 5 indicated none. These statements were: (1) Put suggestions made by people in the work group into operation; (2) Treat all people in the work group as equal; (3) Back up what people under you do; and (4) Reject suggestions for change. Statements 5 to 8 focused on initiating-structure leader behaviour and the respondents were required to indicate in a like manner the frequency of their engagement in the behaviour by encircling the choices from 1 to 5 . These statements comprised: (1) Talk about how much should be done; (2) Assign people in the work group to particular tasks; (3) Offer new approaches to problems; and (4) Emphasize meeting the deadlines.

\section{Participants}

Eighty-four (84) educational leadership students participated in the Perspectives of Leadership course unit after taking the pretest and also took the posttest at the completion of the unit. Out of 84 students 27 (32\%) were potential leaders and the rest were already holding leadership positions in their schools. These positions include: principal, headteacher, coordinator and subject specialist. Eighteen (18) out of the 84 students (21\%) were from the wider private sector educational community and 66 (79\%) were from a faith-based minority school system. To determine the effect of the intervention on the development of expected initiating-structure and consideration leader behaviours among educational leadership students, students' responses for the pretestt and posttest were compared and inferences were drawn. Although the pretest supported a claim that the change in students' leadership behaviours, observed during the posttest, was due to the intervention, the result would have been more convincing if a true experimental design, that is, the Randomized Posttest-Only Control Group Design or the Randomized PretestPosttest Control Group Design had been used (Fraenkel et al., 2012). He argued that the main ingredient in a true experiment design is randomly assigned subjects to a treatment group. A further strength of the experimental design used for the current research could be expected if both treatment and control groups were formed to enable the comparison of the result of the posttest taken by both the groups. Similarly, the research might have produced different results if all educational leadership students held leadership positions and were not in the category of future leaders. 


\section{Data Analysis}

\section{Initial Data Analysis Technique Suggested by Fleishman}

The data gathering and its analysis was guided by Fleishman Pierce and Newstrom (2005b) through the use of Fleishman's Leadership Opinion Questionnaire and his particular data analysis technique in which the scores of each respondent to statements 1, 2 and 3 were subtracted from 6 and then added up the remaining score to the sums of statements 1,2 , 3 and 4 and divided by 4 . The remaining score was considered as the leader behaviour score. Similarly, the score of each respondent to statements 5, 6, 7 and 8 were subtracted from 6 and then added up the remaining score to the sums of statements 5, 6, 7 and 8 and divided by 4 . The remaining score was initiating-structure leader behaviour score. A high score (4 and greater) suggested relatively strong orientation towards particular leader behaviour. A moderate score (above 2 and less than 4) was considered a satisfactory orientation towards particular leader behaviour. A low score ( 2 and less) suggested a relatively weak orientation towards particular leader behaviour.

Table 1

\begin{tabular}{lcccc}
\multicolumn{4}{l}{ Consideration Leader Behaviour } \\
\hline Level & Range & Pretest (\%) & Posttest (\%) & Difference (\%) \\
\hline Low & 2 and less & 46 & 57 & -11 \\
Moderate & above 2 and less than 4 & 50 & 39 & 11 \\
High & 4 and above & 4 & 4 & 0 \\
\hline
\end{tabular}

Table 1 indicates that a reasonable percentage of the participants holding consideration leader behaviour declined. For example the difference between the percentages of moderate level leadership behaviour and low level leadership behaviour during the pretest and posttest was 11 and -11 respectively which indicates that a sizable percentage of students moved from a moderate level of consideration leader behaviour to a low level of consideration leader behaviour. On the contrary, a small percentage of students holding a high level of consideration leader behaviour remained unchanged.

Table 2

Initiating-structure Leader Behaviour

\begin{tabular}{lcccc}
\hline Level & Range & Pretest (\%) & Posttest (\%) & Difference (\%) \\
\hline Low & 2 and less & 68 & 71 & -3 \\
Moderate & above 2 and less than 4 & 18 & 25 & -7 \\
High & 4 and above & 14 & 4 & 10 \\
\hline
\end{tabular}

Table 2 indicates that a gradual reduction of initiating-structure behaviour was observed among the students as the percentages of students holding low and moderate levels of initiating-structure behaviour during the pretest were increased after the intervention (Percentage difference between low level behaviour pretest-posttest = -3; Percentage difference between moderate level behaviour $=-7$ ) and the percentage for the high level of initiating-structure behaviour was reduced reasonably (Difference high level behaviour pretest-posttest $=10 \%$ ). 


\section{Hypotheses Testing}

After the initial data analysis, data were tabulated and further analysed to test the hypotheses using the Statistical Package for Social Sciences (SPSS) 22nd version.

\section{Paired Sampling t-test}

A paired sample t-test was conducted to evaluate: (1) whether or not a statistically significant difference exists among the educational leadership students between their means of average pretest scores and mean scores on consideration leadership behaviour scale after participating in the Perspectives of Leadership course unit of the CELD educational leadership programme. (2) Whether or not a statistically significant difference exists among the educational leadership students between their mean of average pretest scores and mean initiating-structure leadership behaviour scores after participating in the Perspectives of Leadership course unit of the CELD educational leadership programme.

Prior to conducting the paired-sample t-test, normality distribution of data was assessed and to make the data normally distributed twelve (12) outliers were identified and removed. The skewness values for valid cases $(n=72)$ ranged from .51 to 1.92 for average pretest and pretest (consideration) and posttest (insitiating-structure) which were below 1.96 (Fraenkel et al., 2012) indicating that the data were normally distributed.

\section{Hypothesis 1}

Paired sample t-test was run to identify whether or not pre-intervention pretest (MAvePreT $=1.91, \mathrm{SD}=.51$ ) and post-intervention consideration leader behaviour means (MPoTCons $=2.19, \mathrm{SD}=.81$ ) were equal (see Table 4 ). The results of the paired sample t-test were significant, $\mathrm{t}(71)=-2.80, \mathrm{p}<0.007$, indicating that there was a significant difference between the mean of average pretest scores and mean consideration leader behaviour scores of the educational leadership students after participating in the Perspectives of Leadership course unit of the educational leadership programme (see Table 3). Thus the null hypothesis $H_{o_{1}}$ was rejected and the alternative hypothesis $H_{1}$ was accepted.

$$
\begin{gathered}
H o_{1}: \mu_{1}-\mu_{2}=0(\text { Rejected }) \\
H_{1}: \mu_{1}-\mu_{2} \neq 0(\text { Accepted })
\end{gathered}
$$

Table 3

\begin{tabular}{|c|c|c|c|c|c|c|c|c|c|c|}
\hline & & \multicolumn{5}{|c|}{ Paired Differences } & \multirow{3}{*}{$\mathrm{t}$} & \multirow{3}{*}{ df } & \multirow{3}{*}{ Sig. (2-tailed) } & \multirow{3}{*}{$\begin{array}{c}\text { Effect } \\
\text { Cohen's d } \\
d=\mathrm{M} / \mathrm{SD}\end{array}$} \\
\hline & & Mean & Std. Deviation & Std. Error Mean & \multicolumn{2}{|c|}{$95 \%$ Confidence } & & & & \\
\hline & & & & & Lower & Upper & & & & \\
\hline Pair 1 & Ave. Pretest-posttest (Consideration) & -0.28 & 0.86 & 0.1 & -0.49 & -0.08 & -2.8 & 71 & 0.007 & 0.33 \\
\hline Pair 2 & Ave. Pretest-posttest (Initiating-structure) & 0.15 & 0.82 & 0.1 & -0.05 & 1.51 & 1.51 & 71 & 0.136 & \\
\hline
\end{tabular}

Paired Sample t-test 


\section{Hypothesis 2}

A paired sample t-test was used to investigate whether or not the mean of average pretest scores (MAvePreT $=1.91, \mathrm{SD}=.51$ ) and the post-intervention initiating-structure leader behaviour means (MPoTIns $=1.76, \mathrm{SD}=.82$ ) were equal (see Table 1.4). The results of the paired sample $\mathrm{t}$-test were insignificant, $\mathrm{t}(71)=1.51, \mathrm{p}<.136$, indicating that there was no significant difference between the mean of average pretest and mean initiating-structure leader behaviour scores of the educational leadership students after participating in the Perspectives of Leadership course unit of the educational leadership programme (see Table 3). Thus the null hypothesis $\mathrm{Ho}_{2}$ was retained and the alternative hypothesis $\mathrm{H}_{2}$ was rejected.

$$
\begin{gathered}
H o_{2}: \mu_{3}-\mu_{4}=0(\text { Retained }) \\
H_{2}: \mu_{3}-\mu_{4} \neq 0(\text { Rejected })
\end{gathered}
$$

\section{Hypothesis 3}

Table 4 reveals that the post-intervention consideration leader behaviour mean scores (MPoTCons $=2.19, \mathrm{SD}=.81$ ) were greater than the mean of average pretest scores (MAveP$\mathrm{reT}=1.91, \mathrm{SD}=.51$ ). It can therefore be concluded that intervention in the form of teaching of Perspectives of Leadership course unit contributed significantly to develop consideration leader behaviour among the students of educational leadership programme offered by CELD.

\begin{tabular}{lccccc}
$\begin{array}{l}\text { Table } 4 \\
\text { Paired Sample Statistics }\end{array}$ & & & & & \\
\hline & & Mean & N & Std. Dev & S.E Mean \\
\hline \multirow{2}{*}{ Pair 1 Consideration } & Ave. Pretest & 1.91 & 72 & 0.51 & 0.06 \\
& Ave. Posttest & 2.19 & 72 & 0.81 & 0.1 \\
\multirow{2}{*}{ Pair 1 Initiating-Structure } & Ave. Pretest & 1.91 & 72 & 0.51 & 0.06 \\
& Ave. Posttest & 1.76 & 72 & 0.82 & 0.1 \\
\hline
\end{tabular}

Cohen (1988) proposed the Cohen's d technique to calculate standardized difference between two groups. Thus Cohen's $d$ for the difference of means between average pretest and post-intervention consideration leader behaviour scores were calculated as 0.33 (see Table 1.3). The effect size $(\mathrm{d}=0.33)$ indicates that the effect of the intervention on the posttest was significant but medium and the participants' scores after the intervention were at the 62 percentile of the pretest scores indicating 21.3 percent non-overlap distribution of the scores between the pretest and posttest (Cohen, 1988). Thus the null hypothesis $\mathrm{Ho}_{3}$ was rejected and the alternative hypothesis $H_{3}$ was accepted.

$$
\begin{gathered}
H o_{3}: \mu_{1}=\mu_{2}(\text { Rejected }) \\
H_{3}: \mu_{2}>\mu_{1}(\text { Accepted })
\end{gathered}
$$




\section{Hypothesis 4}

Data presented in Table 1.4 identifies that the post-intervention initiating-structure leader behaviour mean scores (MPoTIns $=1.76, \mathrm{SD}=.82$ ) were smaller than the mean of average pretest scores (MAvePreT $=1.91, \mathrm{SD}=.51)$. It can therefore be inferred that intervention in the form of teaching of Perspectives of Leadership course unit contributed insignificantly to develop initiating-structure leader behaviour among the students of educational leadership programme offered by CELD. Thus the null hypothesis Ho4 was retained and the alternative hypothesis $\mathrm{H} 4$ was rejected.

$$
\begin{gathered}
H_{4}: \mu_{3}=\mu_{4}(\text { Retained }) \\
H_{4}: \mu_{3}>\mu_{4}(\text { Rejected })
\end{gathered}
$$

\section{Result}

In order to answer the research question To what extent was the Perspectives of Leadership course unit of the CELD Educational Leadership Programme effective in developing initiating-structure and consideration behaviours to be demonstrated among its participants, the results of the current research were derived from the inferences made from the initial data analysis and hypotheses testing. The subsequent paragraphs highlight two main trends identified from the data analysis.

Trend 1: Intervention provided little guidance to educational leadership students in making choices between initiating-structure and consideration leader behaviours.

The initial data analysis revealed that a decline in percentages of students adopting both initiating-structure and consideration leader behaviour exhibits that studying the Perspectives of Leadership course unit showed the students' inability to make a choice between two extremes of leader behaviours. This signifies that the intervention could not guide the educational leadership students to decide whether they should acquire a leader behaviour which provides guidance for co-workers to solve their problems, complete tasks assigned by the institutes and meet deadlines or adopt a flexible, employeescentred leader behaviour which involves co-workers in decision making and other institutional activities. Such a result compels the educators to challenge the legitimacy of the approaches used to teach the course unit. It is extremely important that the unit lecturers use constructivist learning approaches and allow educational leadership students to construct their own knowledge while working on practical scenarios and bridge the gaps between leadership theory and practice.

Trend 2: Gradual movement from the initiating-structure oriented leader behaviour to the consideration oriented behaviour. 
It was inferred that the Perspectives of Leadership course unit encouraged its educational leadership students to move away from the initiating-structure oriented leader behaviour. The data presented above are inconsistent with Waqar and Siddiqui (2008) who found that educational leaders in Pakistan from private schools would exhibit a reasonably high level of initiating-structure leader behaviour. If initiating-structure and consideration are two extremes of a leader behaviour continuum, then the trend was a gradual movement from the initiating-structure oriented leader behaviour to the consideration leader behaviour. This trend affirms that the educational leadership students taking the Perspective of Leadership course unit were encouraged to be inclined towards more flexible, employee-centred behaviour. These students were expected to support their coworkers in their work related activities and provide them with equal opportunities to participate in institution wide decision making. The result from hypotheses testing indicates that there was a significant difference between the mean consideration and the mean of the average pretest scores of leadership students participating in the Perspectives of Leadership course unit of the educational leadership programme offered by CELD. The result also found that there was insignificant difference between the mean initiating-structure leader behaviour scores and the mean of average pretest scores of the leadership students.

Recent research findings have highlighted the importance of developing both initiatingstructure or transactional or task-oriented behaviour among educational leaders so that they may work for achieving organisational goals through co-workers (Khan et al., 2011). Initiating-structure leader behaviour, however, is associated with a tall structured and operationally rigid bureaucratic organisation (Lunenburg \& Ornstein, 2012). In the current research, a reduced mean of the initiating-structure behaviour during the posttest (MAvePreT $=1.91$ and MPoTIns = 1.76) indicates that the educational leadership students moved from a strong or moderate orientation to a weak orientation towards the initiating-structure oriented behaviour. This trend was considered positive as educational leadership students were gradually moving from a rigid initiating-structure oriented or production-centred behaviour extreme to a flexible consideration or employees-centred extreme (Lunenburg \& Ornstein, 2012). Insignificant difference between mean of average pretest scores and mean initiating-structure leader behaviour was also considered positive because developing initiating-structure behaviour among the educational leadership students at some level was important for preparing them to achieve organisational goals through co-workers (Khan et al., 2011).

Holloway (2012) while citing Northouse suggested developing consideration leader behaviour among educational leadership students to assist them to develop inter-personal relations so that they feel comfortable about themselves, their co-workers and their workplace. Lodhi and Ahmad (2010); Nawab (2012) highlighted the importance of the social or participation perspective for an organisation to work effectively. According to this perspective, employees should work as communities of practice (CoP) and learn from each other while having informal and formal work related interactions at their workplace. The challenge for a leadership programme, therefore, is to pay attention on developing consideration behaviour among educational leadership students, as such behaviour will assist them to create community-like environment within their organisations. In the current study, the value of Cohen's $d(d=0.33)$ indicates that teaching of Perspectives of Lead- 
ership unit was able to develop consideration leader behaviour among the educational leadership students at a medium yet significant level. This trend was considered positive as educational leadership students moved from a rigid behaviour and reduced sense of responsibility (Diamond, Randolph, \& Spillane, 2004) to an increased sense of responsibility and flexible behavioural style.

\section{Conclusion}

The outcome of the current research indicates that teaching of Perspectives of Leadership unit was able to develop the required leader behaviour among the educational leadership students to a medium level. The results of the research strongly indicate the need for a revision of the piloted educational leadership course in content, structure and method of delivery to acquire a high level of significant results. However, the study must be considered within the context of the educational background of 79 percent of the participants whose previous experience of the learning-teaching interplay to graduate and postgraduate levels was the rote learning of textbook answers, reproduced for written examination assessment and their exposure as a leaders was limited and in a closed environment. The Perspectives of Leadership course unit challenged them to a new way of learning and demonstration of the gained knowledge that engaged them in extensive reading, critical analysis, and the formulation of their own positions in relation to the content matter and the application of this knowledge to the practice of leadership within their local work situations. An arguable assumption contained in this contextual reality is that at the pretest stage, a large proportion of the participants were intent on providing responses they presumed the researchers expected and were unfamiliar with the terminology of the pretest statements. Throughout the study of the Perspectives on Leadership unit, the participants gained a greater understanding of initiating structure and consideration behaviours as well as an ability to recognise them in practice and as a result responded to the posttest statements more accurately. A thorough study of the factors that contribute to the development of leader behaviours among leadership students and alignment of the teaching content and teaching approaches of the leadership units with the findings of the study are highly recommended for future researchers. 


\section{References}

Burke, C. S., Stagl, K. C., Klein, C., Goodwin, G. F., Salas, E., \& Halpin, S. M. (2006). What type of leadership behaviors are functional in teams? A meta-analysis. The Leadership Quarterly, 17(3), 288-307.

Cohen, J. (1988). Statistical power analysis for the behavioral sciences. Erlbaum Associates, Hillsdale.

Derue, D. S., Nahrgang, J. D., Wellman, N., \& Humphrey, S. E. (2011). Trait and behavioral theories of leadership: An integration and meta-analytic test of their relative validity. Personnel Psychology, 64(1), 7-52.

Diamond, J. B., Randolph, A., \& Spillane, J. P. (2004). Teachers' expectations and sense of responsibility for student learning: The importance of race, class, and organizational habitus. Anthropology E Education Quarterly, 35(1), 75-98.

Folkman, J. (2010). Top 9 leadership behaviors that drive employee commitment. Available online at: www.zengerfolkman.com.

Fraenkel, J. R., Wallen, N. E., \& Hyun, H. H. (2012). How to design and evaluate research in education. McGraw-Hill: New York.

Guo, W., Dai, R., \& Yang, J. (2016). The effect of leadership task behavior and relational behavior on job performance: Investigating the moderating role of work alienation. Journal of Service Science and Management, 9(2), 97-110.

Hamid, M. A., Ab Rahman, N. M. N., \& Nor, N. M. (2012). Leadership behavior and performance: A case study of Takaful representatives in Malaysia. African Journal of Business Management, 6(6), 2291-2298.

Hashmi, K. (2015). Principals' leadership and human resource development in schools of pakistan: An exploratory study. Journal of Education $\mathcal{E}$ Social Sciences, 3(1), 209-223.

Holloway, J. B. (2012). Leadership behavior and organizational climate: An empirical study in a non-profit organization. Emerging Leadership Journeys, 5(1), 9-35.

Khan, M. M., Ramzan, M., Ahmed, I., \& Nawaz, M. (2011). Transformational, transactional, and laissez-faire styles of teaching faculty as predictors of satisfaction, and extra effort among the students: Evidence from higher education institutions. Interdisciplinary Journal of Research in Business, 1(4), 130-135.

Lodhi, S. A., \& Ahmad, M. (2010). Dynamics of voluntary knowledge sharing in organizations. Pakistan Journal of Commerce E Social Sciences, 4(2), 120-131.

Loew, L., \& Wentworth, D. (2013). Leadership: The state of development programs 2013. Delray Beach, FL: Brandon Hall Group.

Lunenburg, F., \& Ornstein, A. (2012). Educational administration: Concepts and practices. Belmont, CA: Wadsworth Cengage Learning.

Lussier, R. N., \& Achua, C. F. (2007). Leadership: Theory, application, E skill development. Mason, Ohio: South-Western College.

Moorthy, R. (2014). An empirical study of leadership theory preferences among gen $\mathrm{Y}$ in Malaysia. Review of Integrative Business and Economics Research, 3(2), 398-421.

Nawab, A. (2012). The informal learning approaches of teachers in a secondary school in Pakistan. International Journal of Academic Research in Progressive Education and Development, 1(1), 260-267. 
Petrie, N. (2014). Future trends in leadership development. Ottawa, Ontario: Center for Creative Leadership.

Pierce, J. L., \& Newstrom, J. W. (2005a). Leaders and the leadership process: Readings, selfassessments and applications. Boston: McGraw-Hill.

Pierce, J. L., \& Newstrom, J. W. (2005b). Leaders and the leadership process: Readings, selfassessments and applications. Boston: McGraw-Hill.

Robert, W. L. (2012). The impact of motivation and leader behavior on satisfaction in nonprofits. Proceedings of ASBBS, 19(1), 520-543.

Schleicher, A. (2012). Preparing teachers and developing school leaders for the 21st century: Lessons from around the World. OECD publishing, available online at: http://dx.doi.org/10.1787/9789264xxxxxx-en.

Tabbodi, M. L., \& Prahallada, N. (2009). The effects of leadership behavior on efficacy: A comparative study of faculty of two Universities from Iran and India. Journal of Social Sciences, 20(3), 169-173.

Waqar, S. H., \& Siddiqui, K. (2008). A study about the leadership styles of public and private school principals. Journal of Elementary Education, 18(1-2), 5-20.

Webb, K. (2007). Motivating peak performance: Leadership behaviors that stimulate employee motivation and performance. Christian Higher Education, 6(1), 53-71. 